\title{
Utilization of agro-wastes to produce biofertilizer
}

\author{
Soh-Fong Lim $\cdot$ Sylvester Usan Matu
}

Received: 15 July 2014/ Accepted: 21 October 2014/Published online: 4 November 2014

(C) The Author(s) 2014. This article is published with open access at Springerlink.com

\begin{abstract}
The objective of this study was to develop a simple and cost-effective method to produce biofertilizer using agro-wastes. There were five types of agro-wastes being used in this study. They were wastes from watermelon, papaya, pineapple, citrus orange, and banana. Solidstate fermentation method was used to produce biofertilizer, which was then applied into vegetable plantation. Physical property tests were done on the plant samples of 5 weeks of age in order to determine the effectiveness of the biofertilizer. The results of the experiment showed that the plant samples treated with biofertilizer from watermelon, papaya, and banana wastes had promising physical characteristics. Other tests such as analyses of $\mathrm{pH}$ values and potassium content in the biofertilizers were also done in this research. It was found that watermelon biofertilizer had the highest $\mathrm{pH}$ value (5.15). The banana biofertilizer had the highest content of potassium with a content of $3.932 \mathrm{~g} \mathrm{~K} / \mathrm{L}$.
\end{abstract}

Keywords Agro-wastes - Biofertilizer - Solid-state fermentation

\section{Introduction}

Agro-waste is defined as waste which is produced from various agriculture activities. These agro-wastes include

\section{S.-F. Lim $(\bowtie)$}

Department of Chemical Engineering and Energy Sustainability, Universiti Malaysia Sarawak, 94300 Kota Samarahan, Malaysia e-mail: sflim@feng.unimas.my

S. U. Matu

Department of Mechanical and Manufacturing Engineering, Universiti Malaysia Sarawak, 94300 Kota Samarahan, Malaysia manures, bedding, plant stalks, hulls, leaves, and vegetable matter. Agro-waste is usually produced through farming activities. In farming situation, the agro-waste is often useless and will be discarded [1]. The accumulation of agro-waste may cause health, safety, environmental, and esthetic concern. Thus, this represents a problem which requires safe disposal [2].

According to Subba Rao [3] and Caprara et al. [4], agrowastes contain insoluble chemical constituents (e.g., cellulose and lignin) and soluble constituents (e.g., sugar, amino acids, and organic acids). Other constituents are fats, oil waxes, resins, pigment, protein, and mineral. The agrowastes such as decaying part of plants are the primary source of organic matter in soil [3]. Therefore, agro-wastes are the cheapest source that can be used by farmers to improve the fertility of soil.

Biofertilizer is commonly referred to as the fertilizer that contains living micro-organisms and it is expected that their activities will influence the soil ecosystem and produce supplementary substance for the plants [5]. Recently, many studies and research have been focussed on developing and commercializing agro-waste-based biofertilizer. In Malaysia, the use of microbial inoculants in industry started in late of 1940s, and the most accepted biofertilizer product is the mycorrhiza inoculums [6]. There is proposed MINT-MAH joint research during the year 2002-2004 by Rahim [6] and other biofertilizer manufactures such as IBG Manufacturing Sdn.Bhd.

Over the years, there are plenty of interests of using solid-state fermentation (SSF) process in development of various bioprocesses and products. SSF can be defined as a process that occurs in the absence of free water using solid substrates or support [7, 8]. In SSF, microbial growth and product synthesis are affected by various environmental factors such as water activity, moisture 
content, temperature, $\mathrm{pH}$ level, oxygen levels, and concentration [9]. Moisture content is a critical factor on SSF processes because this variable will influence growth and biosynthesis of different metabolites [10-12]. Lower moisture content causes reduction in solubility of nutrients of substrates, low degree of swelling, and high water tension [9]. On the other hand, higher moisture levels can cause reduction in enzymes yield due to steric hindrance of the growth of the production strain by reduction in porosity (inter particle spaces) of solid matrix, thus interfering oxygen transfer.

Thus, the objective of this research was to overcome the problems of the agro-waste accumulation in the environment by utilizing them to produce biofertilizer using SSF method. This study also investigates the applicability of the biofertilizer in vegetable plantation.

\section{Materials and methods}

Agro-wastes

Agro-wastes that were used in this study are wastes from pineapple, watermelon, banana, papaya, and citrus orange. The source was obtained from the nearby fresh market. The agro-wastes were cut into smaller size.

\section{Solid-state fermentation (SSF)}

Solid-state fermentation of agro-wastes was carried out by using the method described by Attiya and Ashour [14]. Five hundred grams of water melon wastes was placed into a polyethene bottle which has a capacity of $2.5 \mathrm{~L}$. Five hundred milliliters of water was added into the bottle. The bottle was then placed in a room with temperature of $298 \mathrm{~K}$ until soluble product is formed. This soluble product was filtered with the fabricated filter (not shown here). The filtered solution is the fermented solution, which is also known as first batch water melon biofertilizer.

Five hundred milliliters of this filtered solution was used as inoculum precursor to the next SSF process with $500 \mathrm{~g}$ new water melon wastes, which were placed in a polyethene bottle. The precursor will increase the rate of fermentation, which minimizes the duration of SSF process. The bottle was then placed in a room with temperature of $298 \mathrm{~K}$ until the fermented mixture is soluble. This soluble product was filtered with the fabricated filter (not shown here). This filtered solution is called second batch water melon biofertilizer.

Agro-wastes from pineapple, banana, papaya, and citrus orange were also used to produce first and second batches of biofertilizer. The procedure is the same as above.
Biofertilizer analyses

$\mathrm{pH}$ and potassium content analyses in the biofertilizers were performed. Purpose of $\mathrm{pH}$ test was to analyze the acidity of the biofertilizers, and this test was done using digital $\mathrm{pH}$ meter. Analysis of potassium content was done to determine the amount of potassium species in the biofertilizers. The analysis was carried out using atomic absorption spectrometer (AAS, Thermo Scientific, AASiCE 3500, UK).

Applicability of the biofertilizer in vegetable plantation

The biofertilizers were applied on the Mustard plant (Brassica Juncea Var Rugosa) samples of 2 weeks of age in order to determine the effectiveness of the biofertilizer. Each batch of the biofertilizers was applied on 100 plant samples. At the same time, controlling samples and another 100 samples were planted in the absence of any fertilizer.

Seeds of plant samples were treated with mixture of biofertilizer and water $(1: 10 \mathrm{~mL} v / \mathrm{v})$. Then, the seeds were exposed to high intensity of sun ray $\left(21-34{ }^{\circ} \mathrm{C}\right)$ for about $12 \mathrm{~h}$ daily. Observation and collection data were performed for each seed after 3 weeks. The collection data were length of the longest roots, number of leaves, and weight of the seeds. The recorded data were analyzed.

\section{Results and discussion}

\section{SSF process}

First batch of fermented wastes is soluble and becomes biofertilizer within 35-40 days. These results are in agreement with the results reported by Kanmani et al. [13]. The fermented solution from the first batch which became soluble and produces enzyme was used as inoculums precursor for the production of second batch biofertilizer. The fermentation time of the second batch is 25-30 days, which is faster than the first batch. This observation was similar with the result published earlier by Attiya and Ashour [14].

Table $1 \mathrm{pH}$ level of biofertilizer

\begin{tabular}{lll}
\hline Type of biofertilizer & $\mathrm{pH}$ Level & Potassium content $(\mathrm{g} \mathrm{K} / \mathrm{L})$ \\
\hline Papaya & 4.45 & 2.245 \\
Pineapple & 4.42 & 2.828 \\
Citrus orange & 4.08 & 0.472 \\
Water melon & 5.15 & 1.529 \\
Banana & 4.52 & 3.932 \\
\hline
\end{tabular}


Fig. 1 Average weight of the Mustard plant samples with the application of different types of biofertilizers

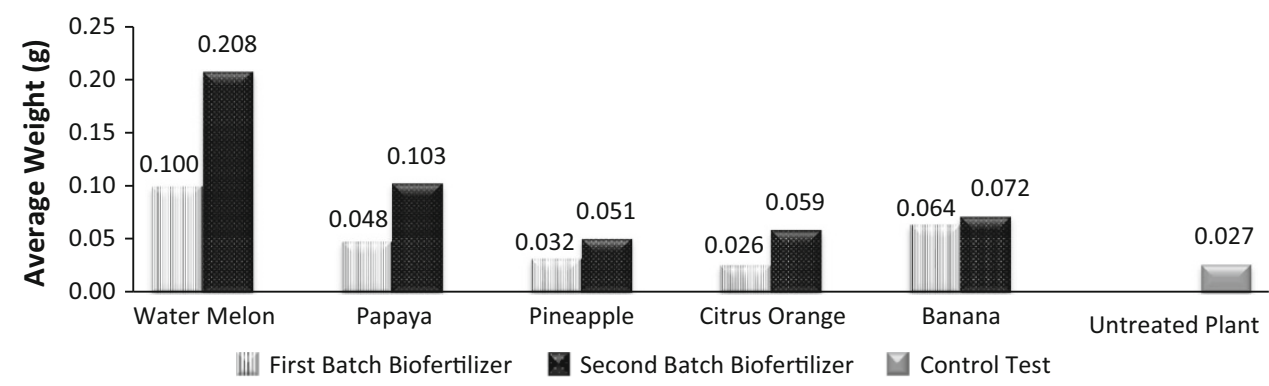

Fig. 2 Average length of longest root in the Mustard plant samples by different types of biofertilizers

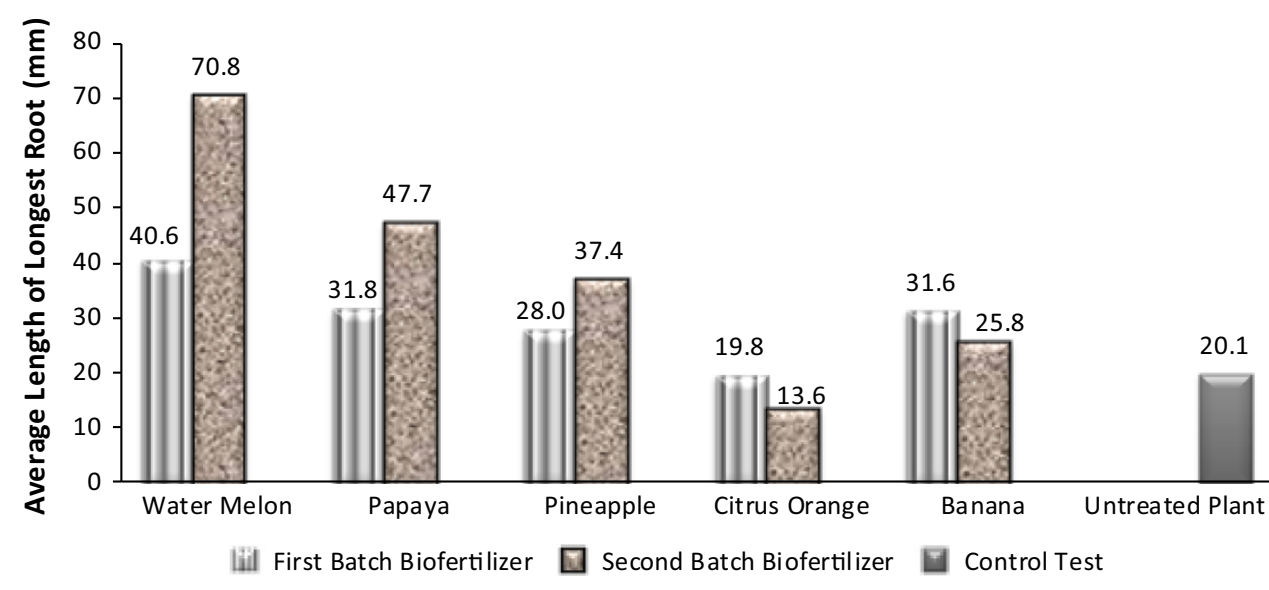

\section{Biofertilizer analyses}

Table 1 shows the results of $\mathrm{pH}$ and potassium content analyses for the five types of biofertilizers. The $\mathrm{pH}$ values show that all the biofertilizers are acidic. The citrus orange biofertilizer has $\mathrm{pH}$ value of 4.08 , which is the lowest among all the other biofertilizers. The biofertilizers from pineapple, papaya, and banana have the $\mathrm{pH}$ values between 4.42 and 4.52 . The biofertilizer from water melon has the highest $\mathrm{pH}$ value which is 5.15 . These results show that citrus orange biofertilizer has the highest acidity value compared to other biofertilizers meanwhile water melon biofertilizer has the lowest acidity in this study.

Banana biofertilizer has the highest potassium content which is about $3.932 \mathrm{~g} \mathrm{~K} / \mathrm{L}$ (Table 1). This is followed by pineapple biofertilizer with content of $2.828 \mathrm{~g} \mathrm{~K} / \mathrm{L}$. The biofertilizers from papaya and water melon waste show results of 2.245 and $1.529 \mathrm{~g} \mathrm{~K} / \mathrm{L}$. The biofertilizer with the lowest content of potassium $(0.472 \mathrm{~g} \mathrm{~K} / \mathrm{L})$ is the biofertilizer produced from citrus orange waste.

Physical analyses of plant samples

The biofertilizers were applied on the Mustard plant (Brassica Juncea Var Rugosa) in order to determine the effectiveness of the biofertilizers. All plant samples were analyzed for the weight, length of the longest roots, and number of leaves.

Figure 1 shows the average weight of the five-week-old Mustard plants with the application of the biofertilizers. These results represent the effect of the biofertilizers on the plants. All the biofertilizers have contributed to the significant increase of the weight of the plants. All the mustard plant samples that used second batch biofertilizers show much higher weight compared to first batch biofertilizers. The plants which were treated with first $(0.100 \mathrm{~g})$ and second $(0.208 \mathrm{~g})$ batches of water melon biofertilizers show more prominent result as compared to other biofertilizers. The biofertilizers made from papaya and banana wastes also show significant result with the average weight of 0.048 and $0.064 \mathrm{~g}$, respectively, for first batch biofertilizers and for second batch biofertilizers, and their average weight is 0.103 and $0.072 \mathrm{~g}$, respectively.

Figure 2 shows the average length of longest root in the Mustard plant samples, which were treated by different types of biofertilizers. The plant samples that were treated with water melon biofertilizer have the highest value of average length of longest root which is 40.6 and $70.8 \mathrm{~mm}$ for first and second batch biofertilizers, respectively. The plant samples which were treated with citrus orange biofertilizer have a lower value in average length of the longest root compared to the plant samples, which were 
Fig. 3 Average number of leaves in the Mustard plant samples by different types of biofertilizers

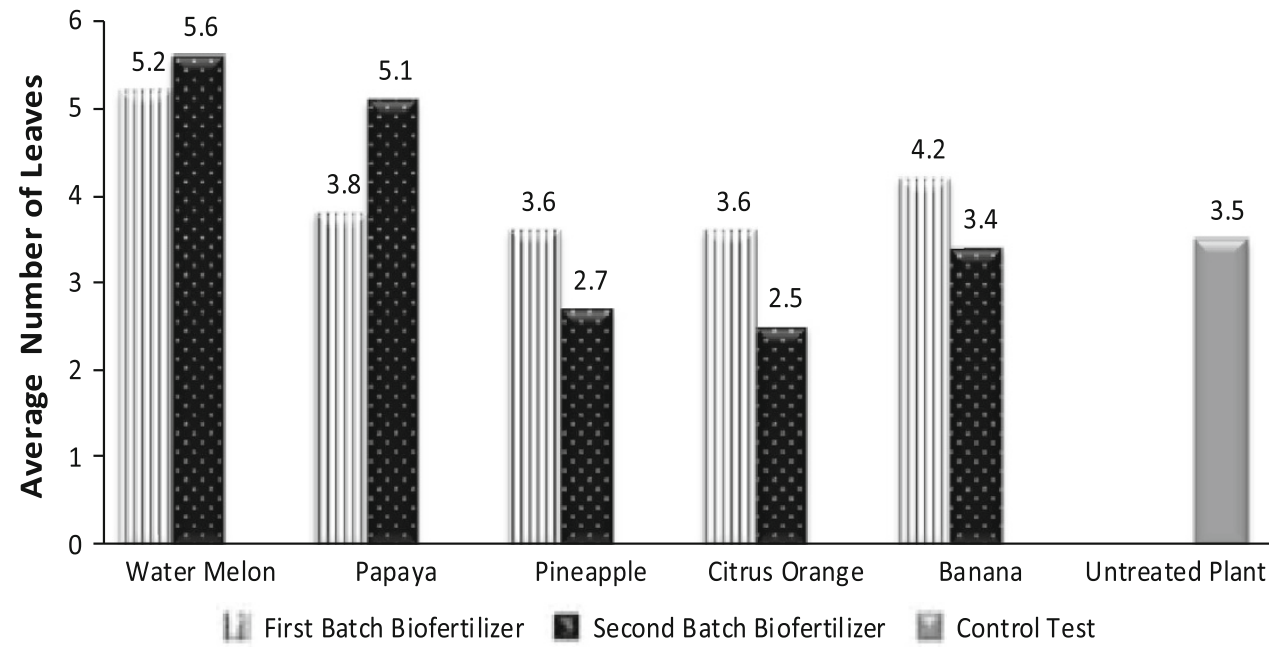

untreated with any fertilizer (Fig. 2). This might be due to the high acidity content of that biofertilizer ("Biofertilizer analyses" Section).

Figure 3 shows the average number of leaves in the Mustard plant samples, which were treated by different types of biofertilizers. It can be seen from Fig. 3 that plant samples which were treated with first batch water melon biofertilizer as well as second batch water melon biofertilizer have the highest number of leaves. On the other hand, plant samples that were treated with citrus orange and pineapple biofertilizers for both of the batches have the lowest number of leaves.

Thus, the physical analyses of the plant samples show that the plant samples which were treated with water melon, pineapple, and banana biofertilizers have gained adequate supply of nutrients from the biofertilizers.

\section{Conclusions}

The present work showed that SSF method is suitable to produce effective and economical biofertilizer, which could increase the yield of crop. Efficient utilization of the biofertilizers is reflected by crop growth rate, which is in fact the gain in weight of the plants. Results also revealed that high acidity content in the biofertilizer will affect the plant growth. Thus, this study has shown that agro-wastes from water melon, papaya, and banana are suitable to be used to produce biofertilizers using SSF method.

Acknowledgments This research was funded by Fundamental Research Grant Scheme (FRGS/02(17)/738/2010(24)) from the Ministry of Higher Education, Malaysia and Osaka Gas Foundation of International Cultural Exchange (OGFICE) Research Grant Scheme.
Open Access This article is distributed under the terms of the Creative Commons Attribution License which permits any use, distribution, and reproduction in any medium, provided the original author(s) and the source are credited.

\section{References}

1. Harris, P.J.C., Alison, M., Smith, G., Kindness, H.M., Kelley, J.: The potential use of waste-stream products for soil amelioration in peri-urban interface agricultural production systems. In: Drechsel, P., Kunze, D. (eds.) Waste Composting for Urban and Peri-Urban Agriculture: Closing the Rural-Urban Nutrient Cycle in Sub-Saharan Africa, pp. 1-28. CABI Publishing, New Work (2001)

2. Sud, D., Mahajan, G., Kaur, M.P.: Agricultural waste material as potential adsorbent for sequestering heavy metal ions from aqueous solutions-a review. Bioresour. Technol. 99(14), 6017-6027 (2008)

3. Subba Rao, N.S.: Biofertilizer in agriculture and forestry, 3rd edn. International Science Publisher, New York (1993)

4. Caprara, C., Colla, L., Lorenzini, G., Santarelli, C., Stoppiello, G., Zanella, D.: Development of a model for technical-economical feasibility analysis of biomass and mud gasification plants. Int. J. Energy Technol. 3, 1-6 (2011)

5. Ngampimol, H., Kunathigan, V.: The study of shelf life for liquid biofertilizer from vegetable waste. AU JT 11(4), 204-208 (2008)

6. Rahim, K. A., 2002. Biofertilizers in Malaysian agriculture: perception, demand and promotion. 2002 FNCA Joint Workshop on Mutation and Biofertilizer, August 20-23, Beijing, China (2002)

7. Veronique, B., Olivier, O., Pierre, C.: Sensors and measurement in solid state fermentation: a review. Process Biochem. 38, 881-886 (2003)

8. Mienda, B.S., Idi, A., Umar, A.: Microbiological features of solid state fermentation and its applications-an overview. Res. Biotechnol. 2(6), 21-26 (2011)

9. Pérez-Guerra, N., Torrado-Agrasar, A., López-Macias, C., Pastrana, L.: Main characterictic and applications of solid substrate fermentation. electronic. J. Environ. Agric. Food Chem. 2(3), 343-350 (2003) 
10. Ellaiah, P.K., Adinarayana, Y., Bhavani, P.P., Srinivasulu, B.: Solid state fermentation method. Process Biochem. 38, 615-620 (2002)

11. Krishna, C., Chandrasekaran, M.: Solid state fermentation method. Appl. Microbiol. Biotechnol. 46, 106-111 (1996)

12. Miranda, R.U., Gómez-Quiroz, L.E., Mendoza, M., Pérez-Sánchez, A., Fierro, F., Barrios-González, J.: Reactive oxygen species regulate lovastatin biosynthesis in Aspergillus terreus during submerged and solid-state fermentations. Fungal Biol. (2014). doi:10.1016/j.funbio.2014.09.002
13. Kanmani, P., Karuppasamy, P.: Studies on lignocellulose biodegradation of coir waste in solid state fermentation using Phanerochaete chrysosporium and Rhizopus stolonifer. Afr. J. Biotechnol. 8(24), 6880-6887 (2009)

14. Attiya, S.H., Ashour, S.M.: Biodegradation of agro-industrial orange waste under solid state fermentation and natural environmental conditions. Egypt. J. Biol. 4, 23-30 (2002) 